This item was submitted to Loughborough's Research Repository by the author.

Items in Figshare are protected by copyright, with all rights reserved, unless otherwise indicated.

An investigation into the use of fluidic devices as gas fuel injectors for natural gas engines

PLEASE CITE THE PUBLISHED VERSION

PUBLISHER

(C) SAE International

LICENCE

CC BY-NC-ND 4.0

REPOSITORY RECORD

Huang, Q., and Rui Chen. 2011. "An Investigation into the Use of Fluidic Devices as Gas Fuel Injectors for Natural Gas Engines". figshare. https://hdl.handle.net/2134/8400. 
This item was submitted to Loughborough's Institutional Repository (https://dspace.lboro.ac.uk/) by the author and is made available under the following Creative Commons Licence conditions.

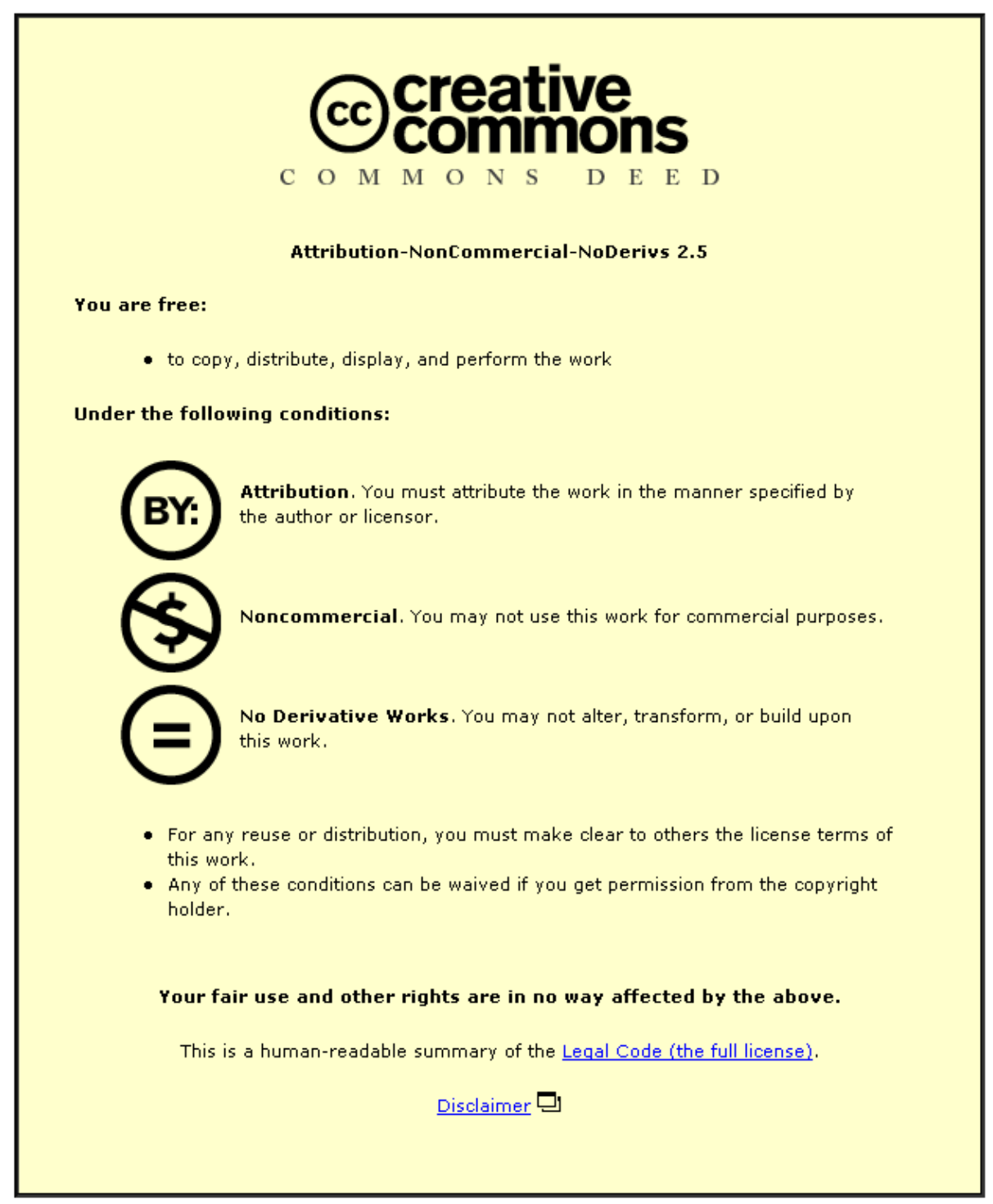

For the full text of this licence, please go to: http://creativecommons.org/licenses/by-nc-nd/2.5/ 


\section{An Investigation into the Use of Fluidic Devices as Gas Fuel Injectors for Natural Gas Engines}

Q. Huang and $R$. Chen

Loughborough Univ.

Reprinted from: Performance of Alternative Fuels for $\mathrm{SI}$ and $\mathrm{Cl}$ Engines (SP-1160) 
The appearance of the ISSN code at the bottom of this page indicates SAE's consent that copies of the paper may be made for personal or internal use of specific clients. This consent is given on the condition however, that the copier pay a $\$ 7.00$ per article copy fee through the Copyright Clearance Center, Inc. Operations Center, 222 Rosewood Drive, Danvers, MA 01923 for copying beyond that permitted by Sections 107 or 108 of U.S. Copyright Law. This consent does not extend to other kinds of copying such as copying for general distribution, for advertising or promotional purposes, for creating new collective works, or for resale.

SAE routinely stocks printed papers for a period of three years following date of publication. Direct your orders to SAE Customer Sales and Satisfaction Department.

Quantity reprint rates can be obtained from the Customer Sales and Satisfaction Department.

To request permission to reprint a technical paper or permission to use copyrighted SAE publications in other works, contact the SAE Publications Group.

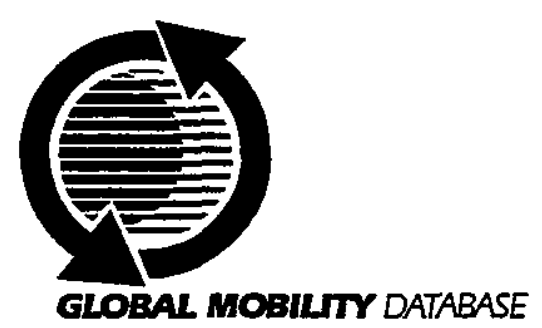

All SAE papers, standards, and selected books are abstracted and indexed in the Global Mobility Database.

No part of this publication may be reproduced in any form, in an electronic retrieval system or otherwise, without the prior written permission of the publisher.

\section{ISSN 0t48-7191}

Copyright 1996 Society of Automotive Engineers, Inc.

Positions and opinions advanced in this paper are those of the author(s) and not necessarily those of SAE. The author is solely responsible for the content of the paper. A process is available by which discussions will be printed with the paper if it is published in SAE Transactions. For permission to publish this paper in full or in part, contact the SAE Publications Group.

Persons wishing to submit papers to be considered for presentation or publication through SAE should send the manuscript or a 300 word abstract of a proposed manuscript to: Secretary, Engineering Meetings Board, SAE. 


\section{An Investigation into the Use of Fluidic Devices as Gas Fuel Injectors for Natural Gas Engines}

Q. Huang and R. Chen

Loughborough Univ.

Copyright 1996 Society of Automotive Engineers, Inc.

\begin{abstract}
A novel gas fuel injector system based on the use of monostable fluidic devices is described in this paper. The proposed system consists of non-moving-part fluidic devices which are capable of operating in a Pulse Width Modulated (PWM) control mode and of handling a large amount of gas flow for engine operations. The system also includes an electro-fluidic interface for fluidic switching and air-gas mixing nozzles for better mixing quality.

Two prototype fluidic injector units were produced and their steady-state and dynamic characteristics were evaluated on a laboratory test rig. The results were compared with those from several commercial gas injectors and it was found that the fluidic injector has a faster dynamic response and a smaller cycle-cycle variations.
\end{abstract}

\section{INTRODUCTION}

Newly legislated exhaust emission standards have revived interest in the use of natural gas as an alternative fuel for automotive engines mainly due to the fact that much less harmful emissions are produced from gas engines than those from gasoline engines. Natural gas consists primarily of methane and has high knock resistance characteristic (typical octane number of 120) which will permit engines to be operated at higher compression ratios resulting in improved fuel economy and reduced emissions. Since natural gas is in a gaseous state, the use of heavy fuel enrichment during engine cold start and transient conditions can be eliminated and as a result, lower exhaust emissions and lower fuel consumption levels can be obtained.
In order to meet increasingly stringent emission legislations, it is necessary to employ a similar air-fuel ratio (AFR) control strategy for gas engines as spark ignition (SI) engines, i.e. stoichiometric AFR control with a Three-Way Catalytic converter (TWC) $[1,2]$. This requires that the fuel metering device must be able to provide an accurate amount of gas fuel under various engine operating conditions and also be able to provide fuel compensations for various ambient and gas storage conditions.

The most commonly used fuel metering device for gas engines is the venturi type carburettor or mixer. The mixer operates on the venturi principle and is designed to admit a stoichiometric air-fuel ratio of 9.5 on the basis of volume flow under one specified ambient condition. However, the required stoichiometric AFR for the TWC operation is based upon a mass flow ratio (16.5:1). Unfortunately, gas carburettors are not capable of providing accurate stoichiometric AFR control on the basis of mass flow under various engine and fuel tank conditions and no compensations can be provided for various gas fuel compositions. Therefore, the use of gas mixers will result in considerable errors in stoichiometric AFR control and result in unsatisfactory emission control $[2,3]$. It was concluded $[2,3]$ that it is essential to utilise a timed gas fuel injection system similar to the one used in SI engines in order to ensure accurate stoichiometric AFR control.

Numbers in brackets designate references at the end of the paper 
Gas fuel injection combined with a modern engine management system not only provides more accurate AFR control but also provides opportunities for utilising positive upstream pressure from the tank to improve the air-fuel mixture quality. The accuracy of stoichiometric AFR control can be ensured for various engine and gas tank conditions through fuel compensations by the engine management system and gas fuel injectors. However, reliable and satisfactory gas fuel injectors with a low manufacturing cost are not yet available $[2,3,4]$.

It is known that the volumetric energy density of natural gas is approximately one order of magnitude lower than that of typical liquid fuels when the gas is injected at 10 bar by the solenoid injector (three orders of magnitude lower at atmospheric conditions). Therefore gas fuel metering devices must be capable of handling correspondingly larger gas volumes to obtain equivalent energy flows. This need for large volume flow per engine cycle requires substantially larger injector components and relatively high pintle lift for the required flow passage area. As a result, high power drive stages are required in the drive circuitry and a relatively slow response will be expected.

Methane is not regarded as an effective lubricant for solenoid injectors, therefore fast wearing and aging could also be expected. It is not unusual to hear complaints about the noise level produced by solenoid gas injectors. This is due to the impact of the armature of large mass on the injector seat which will also contribute to the fast wear and aging of the injectors and relatively high injection pressures used. It is due to the above problems associated with solenoid gas injectors that a novel fluidic device based gas injector is proposed.

The purpose of this project is to investigate the use of fluidic techniques for the gas fuel injector stages for natural gas engines. The proposed fluidic gas injectors are potentially capable of providing more accurate and faster response gas fuel control while meeting the the flow requirements. Considerable cost benefits are also envisaged from the fluidic system due to it's mechanical simplicity. The fluidic injectors can be incorporated into a multipoint gas fuel injection system together with a modern engine management control unit and by doing so both reduced exhaust emissions and improved fuel economy for gas engines can be obtained.

FLUIDIC GAS FUEL INJECTORS

MONOSTABLE FLUIDIC DEVICES - The fluidic devices being considered for natural gas injectors are wall reattachment type monostable fluidic amplifiers. Due to their inherent amplification characteristics, large volumes of gas flow for engine operation can be easily controlled by relatively small flow signals (with a typical gain of 10 plus) through an electro-fluidic interface in a PWM mode. This offers potentials for utilising a low power, fast response interface for fluidic stage switching and for reducing the size and power requirements of the ECU's (Electronic Control Unit) drive circuitry in the engine management system.

Figure 1 shows a monostable device with a biased configuration. The jet flow is initially attached to the right wall (output 1) due to the biased geometry ("Coanda effects"). When sufficient control flow is applied on the positive control port, the main jet flow will be switched to the output 2 and remains on that output so long as the control flow is present. When the control flow is removed the jet flow will be automatically shifted to the output 1 again due to the unbalanced flow entrainment (differential pressure) on both sides of the jet caused by the biased configuration. This method is so-called "Positive control method".

Alternatively, the switching of flow jet to the output 2 can be caused by closing the the vacuum control port cutting off the flow entrainment through this port. The flow attachment on the output 2 will be maintained so long as the vacuum control port is closed off. As the vacuum control port is opened to the medium, the flow jet will be shifted to the output 1 again due to its monostable nature. This switching control method is so-called "Vacuum control method". It can be seen that output 1 represents "stable" side of the fluidic device which the main jet flow always tends to attach to.

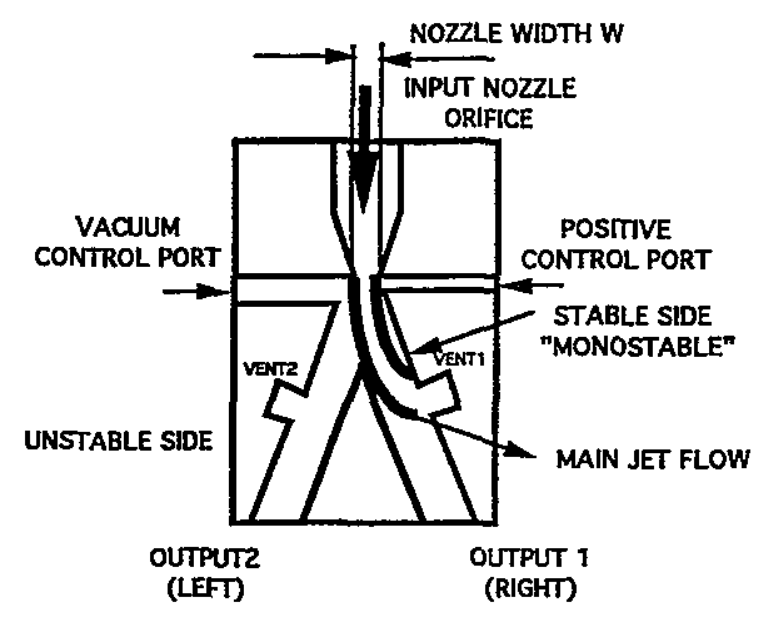

Figure 1 A monostable fluidic device 
SYSTEM OPERATION - Figure 2 shows a schematic set-up of the fluidic gas injector system with the vacuum control switching method employed. The fluidic device is arranged to be "submerged" in an encapsulated gas reservoir under atmospheric pressure Patm. This is to maintain normal wall reattachment and switching operation of the flow jet in the device. A conventional three-stage pressure regulator is used to reduce gas pressure from 200 bar nominal tank pressure to atmospheric one. The output of the regulator is connected to the gas reservoir and therefore an atmospheric pressure condition in the reservoir can be maintained.

A low pressure gas pump or compressor is connected to the other side of the gas reservoir and is used to provide a supply of gas flow to the fluidic device main supply nozzle. When the solenoid actuator is in the closed position cutting off the flow entrainments into the vacuum control port of the device, the main jet flow will be attached to the output 2 (unstable side), which is open to the reservoir itself (unused spill flow). Under such conditions, the gas flow will simply be circulated around the pump, fluidic device and the reservoir.

When the solenoid is energised by drive pulses from ECU, the valve opens allowing the gas flow in the reservoir to be entrained into the device through its vacuum control port. This will cause the main flow jet to be switched to the output I (stable side) due to its monostable nature. The gas flow will then be introduced into the engine manifold through an air-gas mixing nozzle. The fuel flow jet will be maintained on the stable side output 1 so long as the solenoid valve is kept open.
As the solenoid is de-energised, the valve closes and no more flow will be entrained into the device from the vacuum control port. As a result, the main jet flow switches back to output 2 (i.e. reservoir) due to unbalanced pressure across the main jet flow. It can be seen that fuel flow delivered into the engine is determined by the steady-state flow rate at the output 1 and pulse period applied on the solenoid interface by the ECU.

Due to the amplification characteristics of fluidic devices, the mass flow of gas through the vacuum control port causing jet switching is only a fraction (less than 10\%) of the main jet flow delivered into the engine. Therefore, the demand for the solenoid interface has been greatly reduced and a low power, low flow rate and fast response miniature solenoid or equivalent device can be used. In this arrangement the gas pump is required to provide the whole amount of gas flow needed for the fluidic device. Constant gas flow into the the reservoir at atmospheric pressure from the regulator will ensure that the reservoir will not "dry out" and atmospheric pressure Patm within the reservoir can always be maintained.

The purpose of the air-gas mixing nozzles is two fold; one is to introduce an auxiliary air flow from the upstream of the air throttle plate (not shown in this figure) to assist gas mixing; the other, probably more significant, is to maintain atmospheric pressure at the output of the fuel discharge tube inside the nozzle (not shown) thus preventing the fuel jet flow inside the fluidic stages from premature switching to the output 1 under engine manifold depression and pressure fluctuations. Such techniques were used in the previous fluidic gasoline injector system

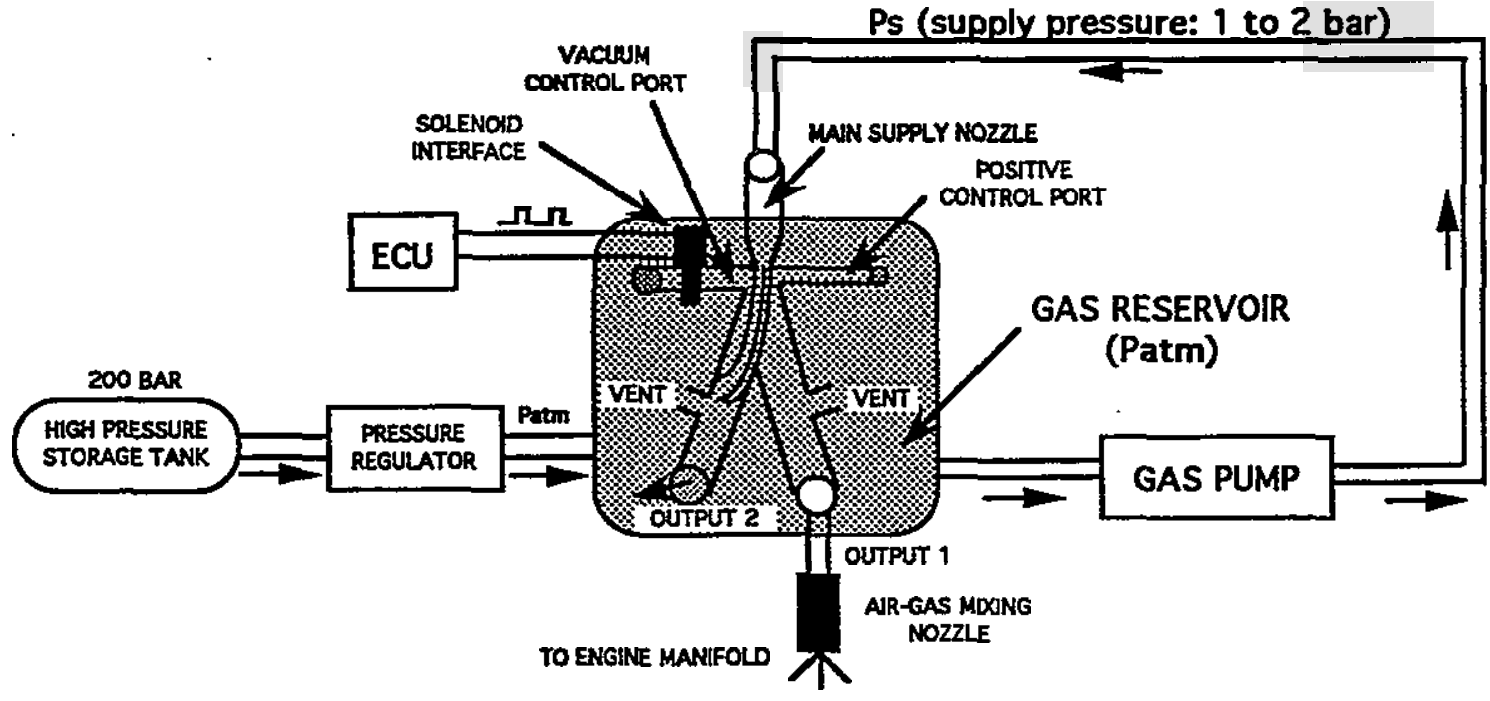

Figure 2 A schematic arrangement for the fluidic injector system (vacuum switching method) 
developed by the author $[5,6,7]$ and it is believed that it is equally applicable to the gas injector arrangement.

An alternative solution is also under consideration by fitting a small one-way valve between the fluidic stage and the engine manifold. The valve will be fully open when the fuel flow is present in the fluidic output allowing the fuel to be delivered into the manifold; and the valve will be closed by a light spring when the fuel is in the other output directing the fuel back to the main reservoir. By doing so, the effects of the manifold vacuum conditions on the fluidic stage can be removed.

A positive switching control method can also be used. This can be achieved by placing the solenoid interface at the positive control port allowing the main jet flow to be attached on the output 1 (stable side). The output 2 will be connected to the mixing nozzle and engine manifold. For this arrangement a minimum control pressure for fluidic switching is required depending on the value of supply pressure.

BENEFITS OF FLUIDIC INJECTORS The fluidic devices are very reliable due to having no moving parts and they can be produced at low manufacturing costs due to their mechanical simplicity. The fluidic injector offers capability for handling large amount of gas flow and fast and accurate fuel metering for stoichiometric AFR control. It overcomes the weakness of both gas carburettors and solenoid injectors and it potentially offers considerable benefits of improved air-fuel mixture preparation and reduced exhaust emissions for natural gas engines.

The improved switching performance and the reduced switching-off delay in particular will result in wider dynamic flow range and improved turn-down ratio for the gas injectors. This will ensure a highly accurate stoichiometric AFR control for a wide range of engine operating conditions and will reduce exhaust emissions from gas engines.

Due to amplification characteristics of the fluidic devices, the demand for the solenoid interface has been greatly reduced and a low power, low flow rate and fast response miniature solenoid or equivalent device can be used. This will reduce the size and power requirements of the drive stages in the ECU.

It is believed that the fluidic gas injector provides an unique opportunity for using a multipoint gas fuel injection system for natural gas engines and will bring gas engine fuel control technology to the same level as that of the well established SI engine Multi-Point Injection (MPI) systems. It's simplicity and low manufacturing cost can also allow such systems to be used not only in Natural Gas Vehicles (NGV's) applications but also in stationary gas engines.

\section{EXPERIMENTAL WORK}

The initial experimental work is focused on two prototype fluidic devices developed in Loughborough University and manufactured by Preci-spark Ltd. Their steady-state flow delivery and dynamic switching characteristics together with cycle to cycle variability were evaluated on a laboratory test rig. Several commercial solenoid injectors were also tested and the results from the fluidic system were compared with those from commercial injectors. A separate test rig including a reservoir enclosure together with a three-way regulator and a recirculating pump was also set up and it is used to investigate the pressure stability in the enclosure under spill flow and vent flow conditions and to prove that the operation of the fluidic injector will be unaffected by the added reservoir enclosure.

STEADY-STATE TESTS - The potential of flow handling capability by the fluidic device was estimated by the steady-state flow tests operating on air. Figure 3 \& Figure 4 show the output pressure-flow characteristics of two prototype fluidic injectors with main input orifice size of $1 \mathrm{~mm}$ (width) by $2 \mathrm{~mm}$ (depth) and 1.5 $\mathrm{mm}$ by $3 \mathrm{~mm}$ respectively. These results were obtained by varying input supply pressure and output restricting nozzle size. It can be seen that a larger output flow (i.e. steady-state flow in Standard Litre per Minute or SLM) can be obtained for a less restricted output (i.e. larger nozzle size) and for the same supply pressure conditions.

It is known that a typical maximum gas flow requirement for a two litre, four cylinder gas engine is about $400 \mathrm{litre} / \mathrm{min}$., or $100 \mathrm{litre} / \mathrm{min}$. per cylinder (i.e. per injector) at atmospheric pressure (SLM). It can be seen from Figure 3 that for the smaller device ( $1 \mathrm{~mm}$ by $2 \mathrm{~mm}$ ) an output of 55 SLM can be obtained at the supply pressure of $140 \mathrm{kPa}$ or 20 pounds per square inches (psi) and at the output nozzle size of $3 \mathrm{~mm}$ in diameter. For the larger device $(1.5 \mathrm{~mm}$ by 3 $\mathrm{mm}$ ), however, an output of 100 SLM can be obtained at the supply pressure of $140 \mathrm{kPa}$ and the output nozzle size of $3 \mathrm{~mm}$ in diameter, as shown in Figure 4. Therefore, a single device of the large version would be suitable for a 2 litre engine flow requirement and two stacked devices of the smaller version would be required for the same 
sized engine application.

For larger gas engine applications, several more basic fluidic devices can be stacked together with appropriate channels connected internally providing required larger steady-state flow rates. The advantages of stacked arrangement are the flexibility of adapting the fluidic unit for various engine sizes and avoidance of possible slow response time associated with excessively large fluidic devices.

Figure 5 shows the calculated dynamic flow delivery by the fluidic injector (the larger version) based on the steady state flow characteristics obtained in Figure 4. It can be seen that the higher the supply pressure, the higher the flow delivery per injection. The proposed supply pressure for the fluidic unit is between $140 \mathrm{kPa}(20 \mathrm{psi})$ and $175 \mathrm{kPa}$ (25 psi) as adequate steady-state flow can be obtained from

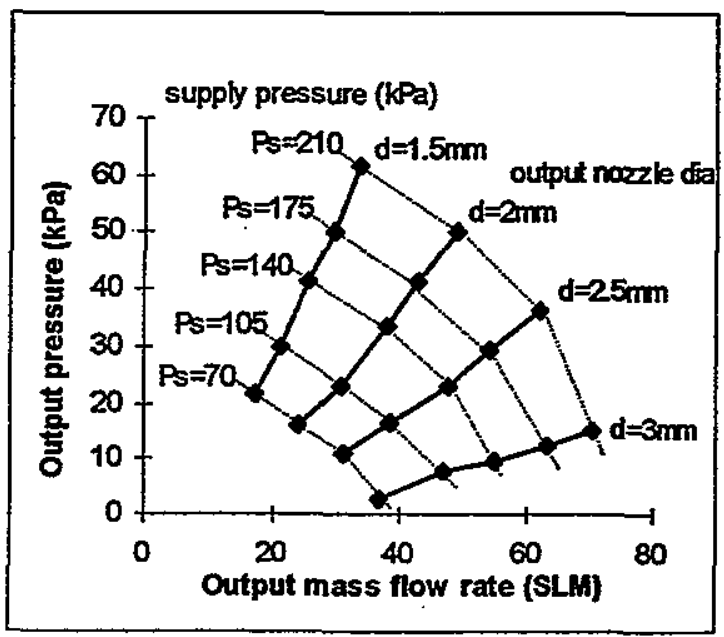

Figure 3 Steady-state output pressure-flow characteristics for the 1st prototype fluidic device

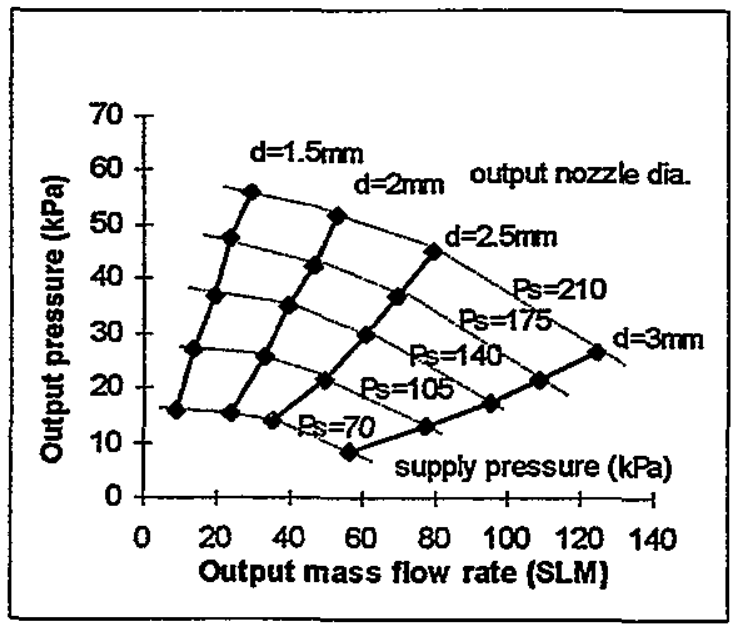

Figure 4 Steady-state output pressure-flow characteristics for the 2 nd prototype fluidic device these conditions.

The dynamic flow delivery by the fluidic unit was further compared with those from commercially available Servojet solenoid injectors (data provided by the manufacturer) and the result is shown in Figure 6. Three types of Servojet units are quoted here, namely SP014, SP021 and SP051 and the pressure for these injectors is $7 \mathrm{bar}$ (700 $\mathrm{kPa}$ or $100 \mathrm{psi}$ ). It can be seen that the dynamic flow delivery by the larger version of the fluidic device with input nozzle size of $1 \mathrm{~mm}$ by 3 $\mathrm{mm}$ is slightly larger than that from the SP051, which is the smallest Servojet unit here. In order to achieve the flow delivery by the SP014, which is approximately twice as much as the one by the SP051 and the larger fluidic unit, two fluidic devices can be stacked together as described above to give the required flow delivery for larger engine applications.

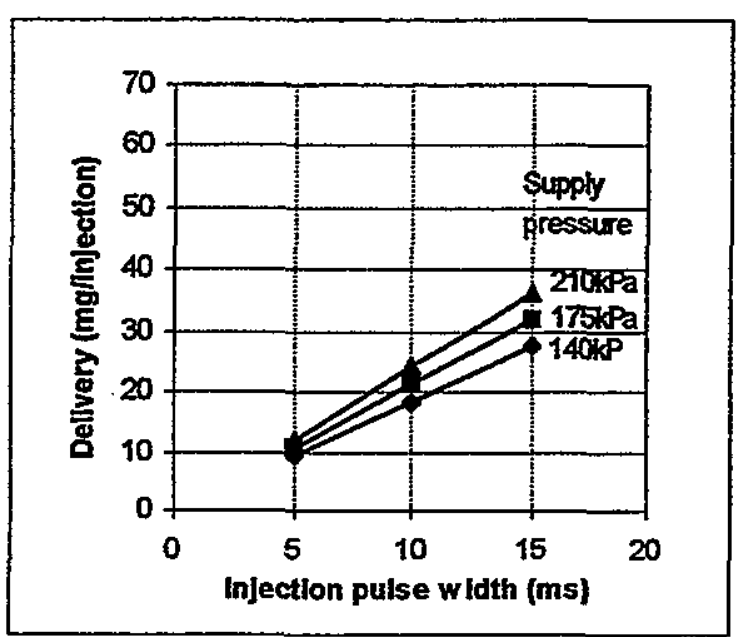

Figure 5 Dynamic flow delivery by the second fluidic injector

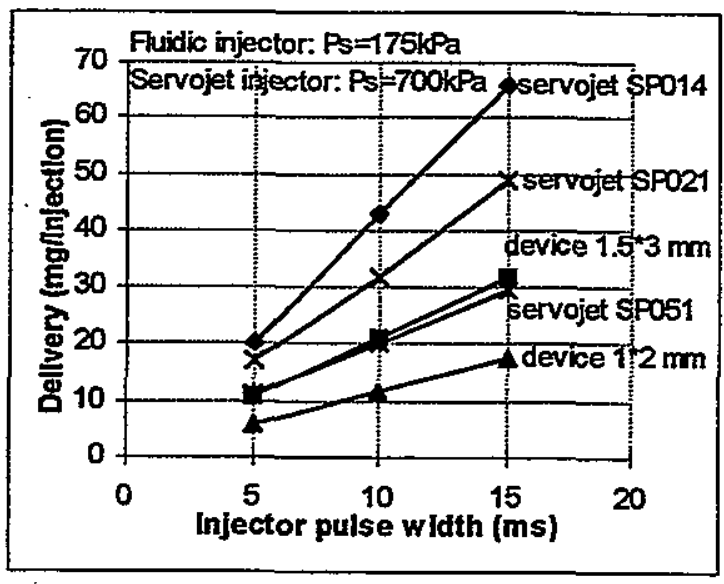

Figure 6 Comparison of the dynamic flow delivery between the fluidic and Servojet injectors 
DYNAMIC TEST RIG AND INSTRUMENTATION - In order to evaluate dynamic switching characteristics of the fluidic injector units and to compare them with those from some commercial gas injectors, a laboratory test rig with a compressed air supply and control board together with appropriate instrumentation was set up. Figure 7 shows a schematic arrangement for the dynamic tests of the fluidic injector. Two fast response Entran pressure transducers (type EPI-M4 ) were used. One was used to detect the response of the solenoid interface (i.e. the control flow signal) to the drive pulses; the other one is used to detect the response of the fluidic stage to the control flow.

Figure 7 shows the arrangement for the vacuum switching control method with the solenoid interface being placed at the vacuum port of the fluidic device. For dynamic testing using positive switching method, the solenoid interface should be placed at the positive control port of the device. The solenoid interface chosen is a conventional central fuel injector (CFI) used in Ford 1.4 litre engines. The solenoid drive circuitry operates in a "peak and hold" mode(type
CS-453) and it was specially designed for fuel injector use for rapid opening and closing.

A PC based data acquisition system was used to collect and analyse switching responses of the fluidic devices and their cycle-cycle switching variability. The software used in the PC is called "LabView" developed by National Instrument. An Amplicon data acquisition board (DAQ board) was chosen instead of the DAQ board from National Instrument after considering its low costs. An advanced linking driver had to be developed by the authors in order to operate the Amplicon DAQ board in LabView language satisfactorily.

DYNAMIC TESTS ON THE FIRST PROTOTYPE DEVICE - The first prototype fluidic device was produced based on the scaledup version of the existing device which was used for the liquid fuel injector in a previous work $[5,6,7]$. The input nozzle orifice size of this prototype device is $1 \mathrm{~mm}$ width by $2 \mathrm{~mm}$ depth. The objective of the dynamic tests on this device is to establish its dynamic capability and the solenoid interface response and to compare the results from

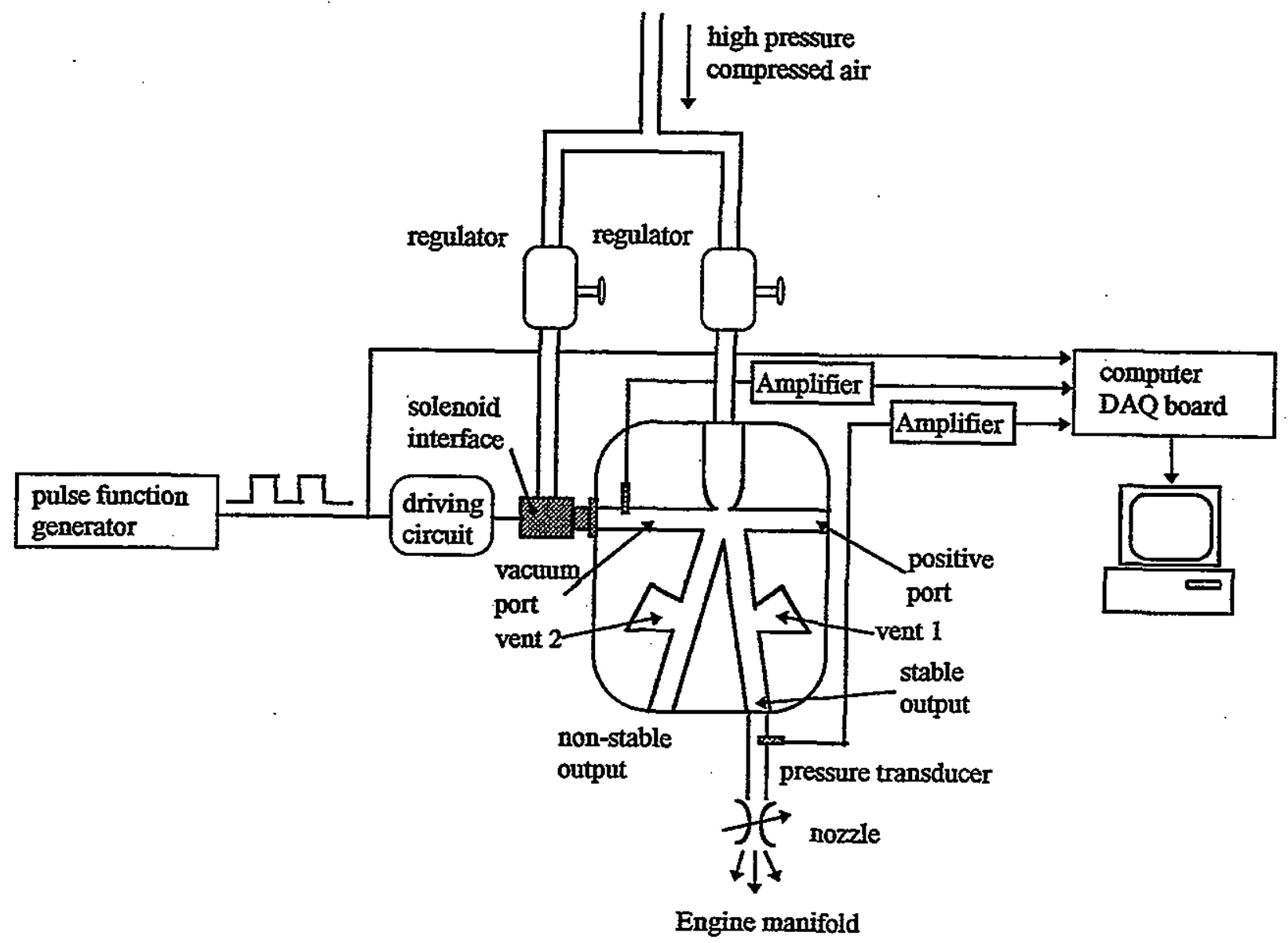

Figure 7 A schematic arrangement of dynamic tests of the fluidic injector 
two switching control methods, namely positive and vacuum switching.

Figure 8 and Figure 9 show the results of the response times of the fluidic stage to the control flow signals from the solenoid interface when positive switching method is used. It can be seen that as control flow pressure increases, the switching-on delay reduces for all supply pressure conditions. This is due to the increased control flow momentum by a higher control pressure resulting in a more rapid jet switching action within the fluidic stage. However, under the same control flow pressure condition, a higher supply pressure will result in a slower switching. This is because a high supply pressure flow possesses a higher flow inertia.

The switching-off delay of the fluidic stage does not seem to be affected considerably by the

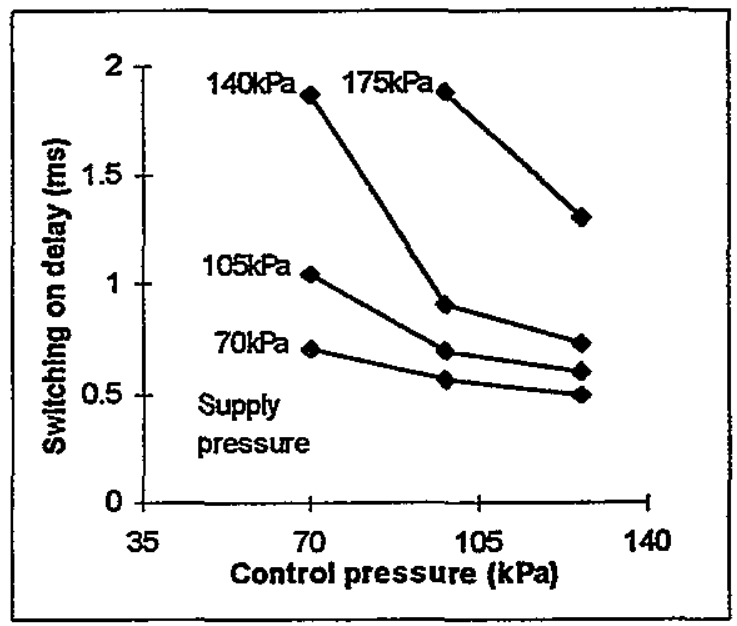

Figure 8 Switching-on delays of the fluidic stage to the control flow signals

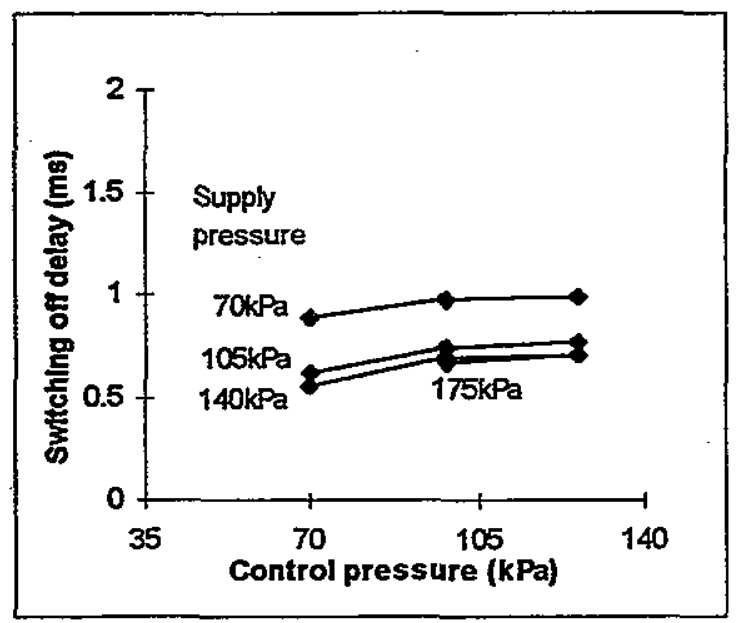

Figure 9 Switching-off delays of the fluidic stage to the control flow signals supply pressure or control pressure. This is because the switching of the jet flow from the unstable output to the stable one, when the drive pulse (i.e. control flow) is removed from the solenoid, largely depends on the biased geometry of the monostable design and therefore the delay time is irrelevant to the external parameters [8].

Figure 10 \& Figure 11 show the response of the solenoid interface (i.e. control flow signals) to the drive pulses. It can be seen that both switching-on and switching-off delays of the solenoid are more or less independent of the control pressure or supply pressure used and they are in the region of $1.1 \mathrm{~ms}$ and $0.9 \mathrm{~ms}$ respectively. It was found later that the response of the solenoid is not affected by the switching method used, and both switching-on and -off delays of the solenoid remains unchanged when a

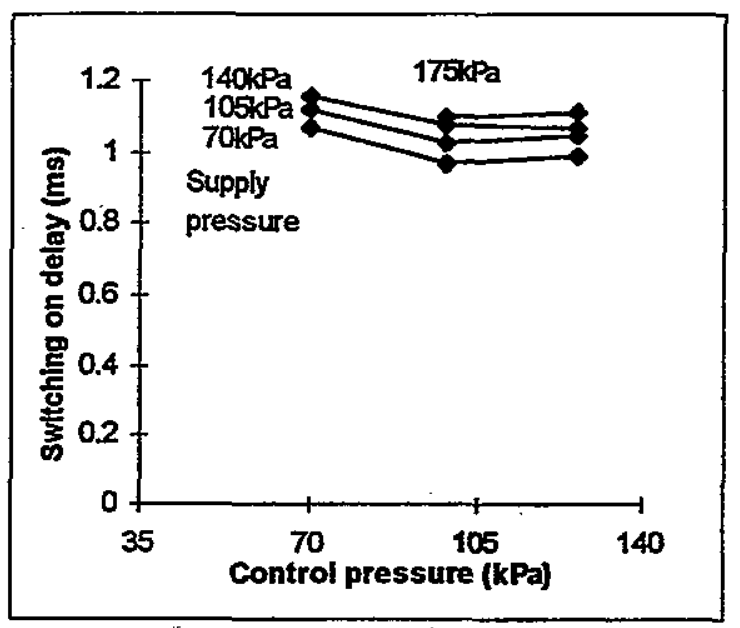

Figure 10 Response of the solenoid interface (i.e. control flow signals) to the drive pulses

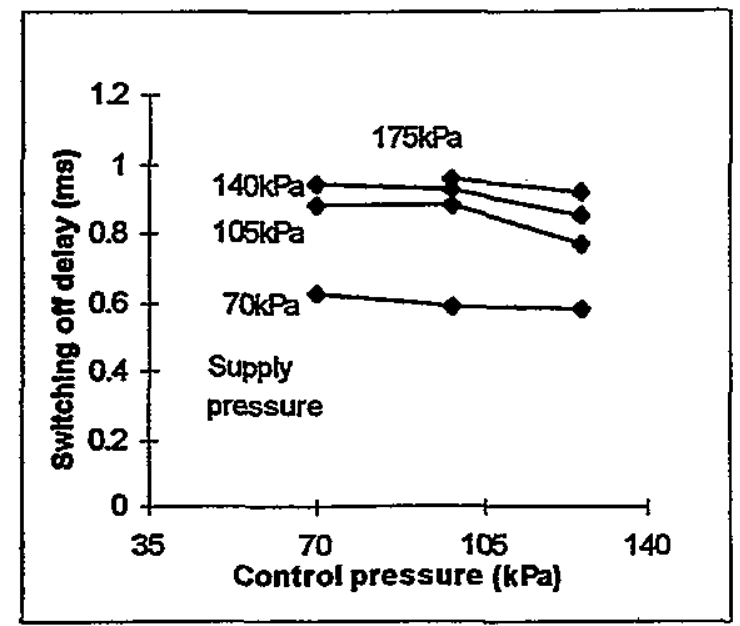

Figure 11 Response of the solenoid interface (i.e. control flow signals) to the drive pulses 
vacuum switching method is employed. Figure 12 \& Figure 13 show the total switching-on and -off delays by the fluidic injector unit with solenoid and fluidic delays added together. It is the total delays which will be used to compare the performance of the fluidic injector against commercial injectors.

In order to compare the fluidic response characteristics with those from vacuum switching control, the solenoid interface was placed at the vacuum port as described in Figure 7. The total switching-on and -off delays were obtained and the results are shown in Figure 14 \& Figure 15. It can be seen from Figure 14 that the total switching-on delay was reduced by up to $2 \mathrm{~ms}$ in the vacuum switching arrangement. Since the solenoid delay remains unchanged $(1.1 \mathrm{~ms}$ for -on delay, as mentioned above) for the two switching arrangements, any reduction in total switching-on

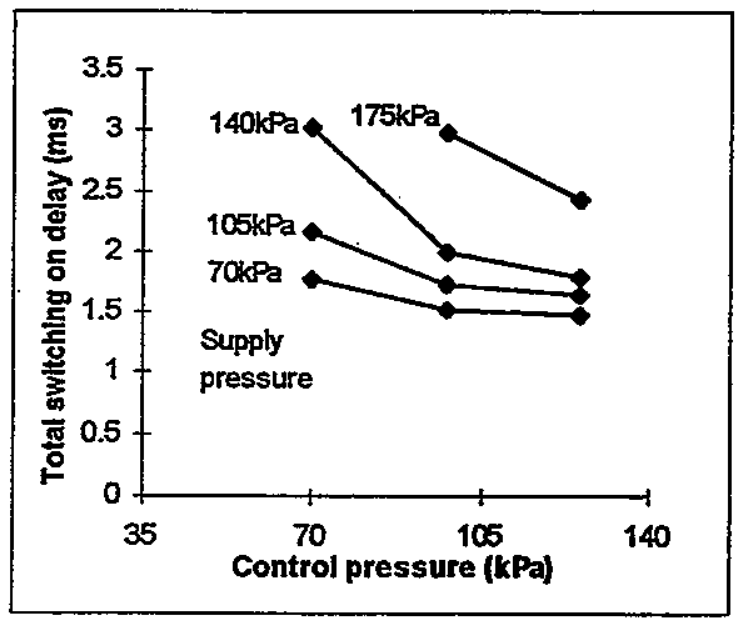

Figure 12 Total switching-on delays by the fluidic injector

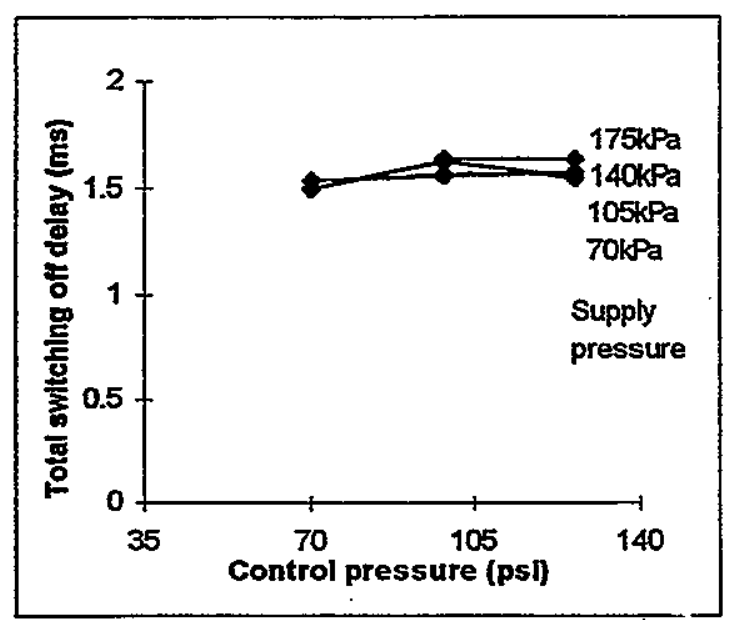

Figure 13 Total switching-off delays by the fluidic injector delay must be due to the improvement in the response of the fluidic stage.

The improvement in the fluidic response by the vacuum switching method can be explained as follows. When the drive pulse is applied on the solenoid, the valve opens allowing the fuel flowing through the vacuum port into the fluidic device. The main jet flow will switch to the stable side spontaneously due to the biased monostable nature. Additional control flow pressure will provide extra momentum resulting in a even faster switching action. In the positive switching arrangement, however, the main flow jet is initially attached to the stable output and in order to cause the jet to switch to the unstable side, a higher positive control pressure is required. The overall effect is that the switching-on response of the fluidic stage by the positive switching method is considerably slower than that by the vacuum

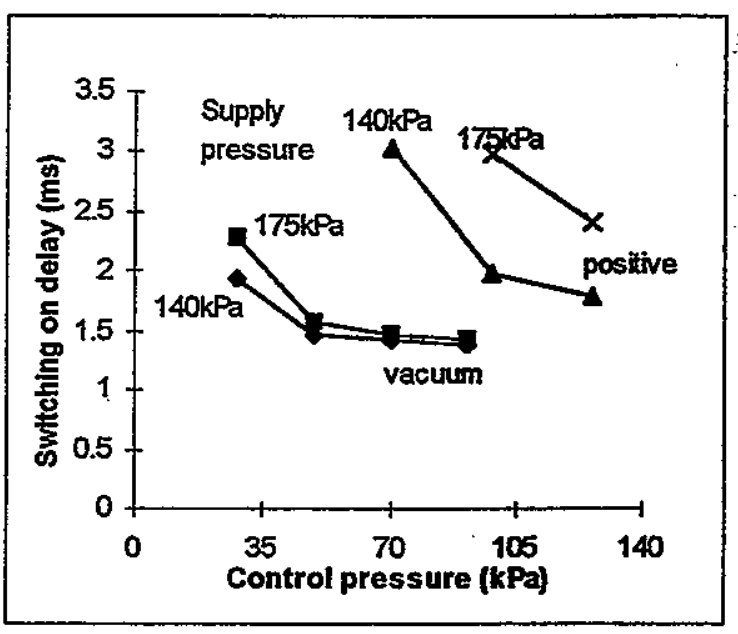

Figure 14 Comparison of switching-on time by the positive and vacuum switching methods

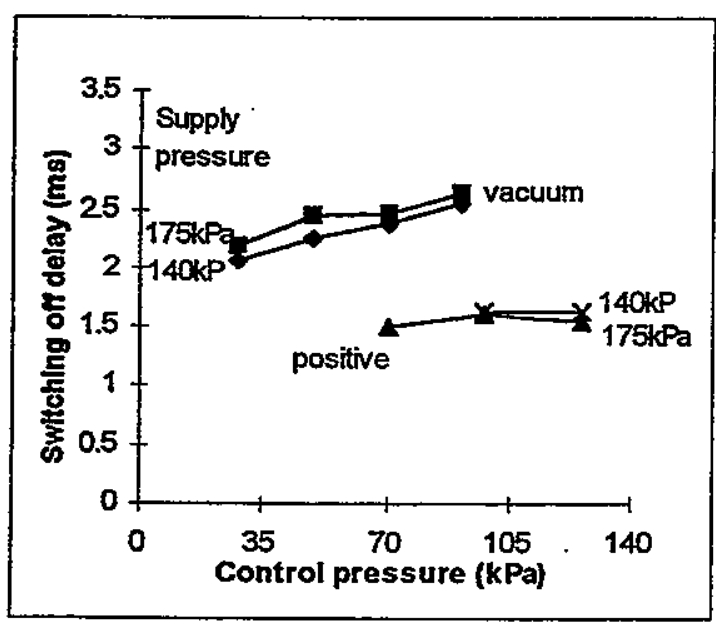

Figure 15 Comparison of switching-off time by the positive and vacuum switching methods 
switching method.

On the other hand, the switching-off response of the fluidic stage by the vacuum switching method is more sluggish than that by the positive method and the difference is in the region of $1 \mathrm{~ms}$. as shown in Figure 15. It is considered that the main reason for this result is due to the fact that a relative long time is required to to establish a sufficient pressure differential across the main flow jet causing it to switch from the stable side to the unstable one. A solution to this problem will be discussed in a later section.

It can be concluded from the above discussions that for the fluidic stage, switching from the stable side to the unstable side is always more difficult regardless which switching method is used. There is no clear favourable choice between the two switching method for the basic fluidic device arrangement. However, when a small modification is made on the fluidic port and vent arrangement, the vacuum switching will show a clear advantage. This will be discussed later.

The repeatability tests for the cycle-cycle switching variability can further prove the above conclusion. Figure 16 \& Figure 17 show the standard deviation (SD) for both -on and -off delays by the two methods. It can be seen that the SD for the switching-on delay by the positive method (i.e. from stable output to the unstable one) is consistently worse than that by the vacuum method (i.e. from unstable output to the stable one). Similarly, the SD for the switching-off delay by the vacuum method is consistently worse than that by the positive method. To conclude, the switching from unstable output to the stable one always gives a better switching repeatability and consistency.

DYNAMIC TESTS ON THE SECOND PROTOTYPE DEVICE - Subsequent to the first prototype, a second prototype device with an input orifice size of $1.5 \mathrm{~mm}$ (width) by $3 \mathrm{~mm}$ (depth) was produced. This is to increase the flow handling capability by a single device. Although for large engine applications, several basic devices can be stacked together to provide required flow, it is more convenient to have a few basic devices so that different combinations can be made for different engine requirements. It was found that the $1.5 \mathrm{~mm}$ by $3 \mathrm{~mm}$ device is capable of providing sufficient gas flow for a 1.6 litre to a 2 litre engine, when a supply pressure of $1.5 \mathrm{bar}$ (22 psi) and a $3 \mathrm{~mm}$ output nozzle are used. The steady-state flow results were discussed already in an early section.

Initial evaluations on this large device

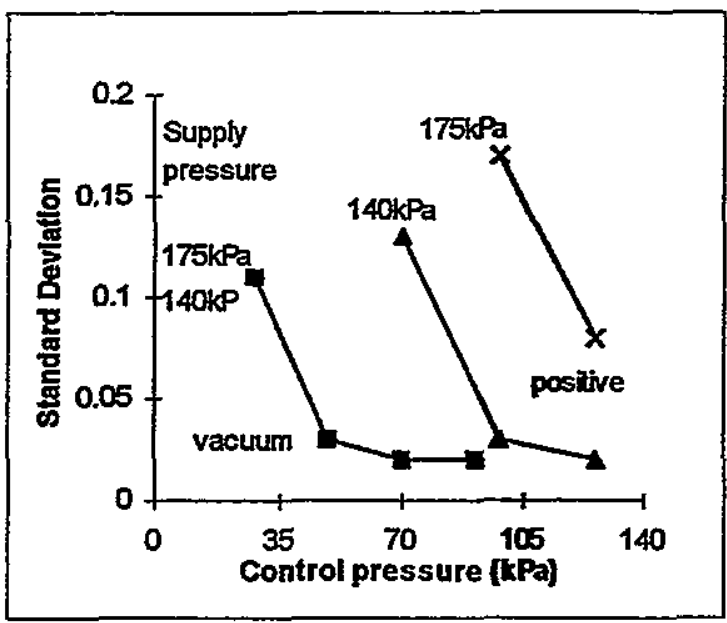

Figure 16 Standard deviation (SD) of the switching-on response by the two methods

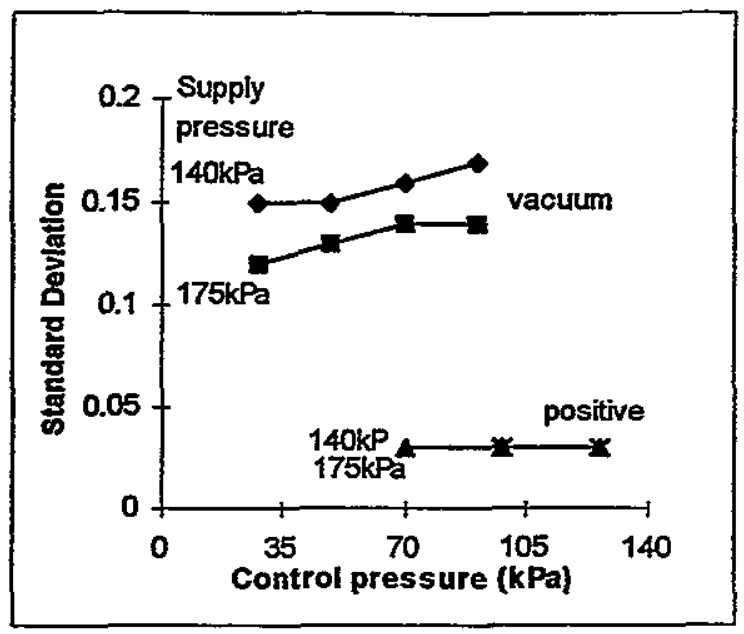

Figure 17 Standard deviation (SD) of the switching-off response by the two methods

showed that it was unable to operate under a positive switching control due to insufficient control flow provided by the same solenoid interface. Therefore only vacuum switching method was used for the second device. Similar response characteristics to those from the first device were obtained and the switching-off performance (i.e. from the stable output to the unstable one) is again unsatisfactory.

In order to reduce the switching-off delay and to improve the SD of the fluidic stage, a small modification was made to the basic device. Figure 18 shows the modified version with positive control port connected with the vent on the same side (stable side). Such a connection can be easily made internally for production units and no interference with the device operation is 
envisaged. Figure 19 \& Figure 20 show the comparison of response times from the basic device and the modified version when a vacuum switching control is used.

It can be seen that there is a slight increase (4 to $5 \%$ ) in switching-on delay when the modified version is used. However, in the gas reservoir enclosure arrangement where a recirculating pump is used, there is actually an improvement in this switching-on time. This will be discussed later. For the switching-off delay, the modified device showed a considerable improvement in the response time and it is reduced by about $20 \%$ as shown in Figure 20 . Also the cycle-cycle repeatability (i.e. SD) of the switching-off response is improved by up to $38 \%$ in the modified device as shown in Figure 21.

The reason for the improvement in the switching-off performance of the modified version can be explained as follows. During the fuel delivery period, the main flow is attached to the stable output. Due to a slight restriction at the output by the nozzle orifice, some fuel may flow out of the device through the vent on the stable side. When this vent is connected to the positive control port, a pressure which is slightly higher than an atmospheric one may be established at that port. However, this pressure is not sufficiently high to cause the main flow to switch back to the unstable side. This is the case that is required, otherwise the flow switching would have become uncontrollable by the solenoid interface. When the drive pulse is removed, the control flow at the vacuum port is cut off causing the pressure at that port to collapse. The presence of a slight high pressure at the positive port will accelerate the process of establishing a sufficient high pressure differential cross the main jet, which determines the switching-off speed of the fluidic device.

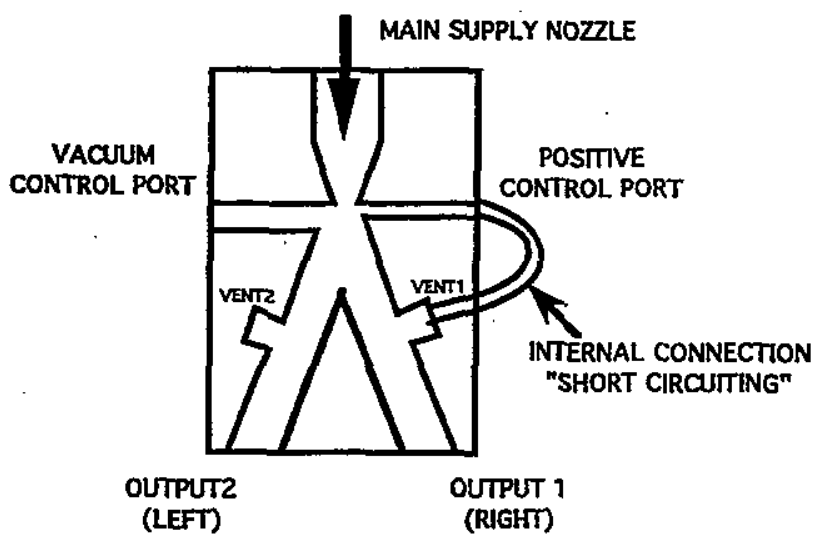

Figure 18 A modified version of the fluidic device with connected control port and the vent

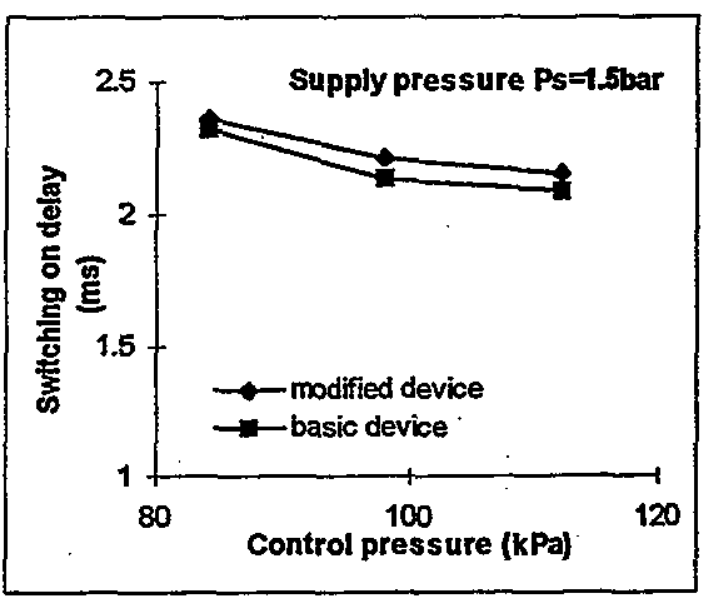

Figure 19 Response times (-on) from the basic device and the modified one (vacuum switching)

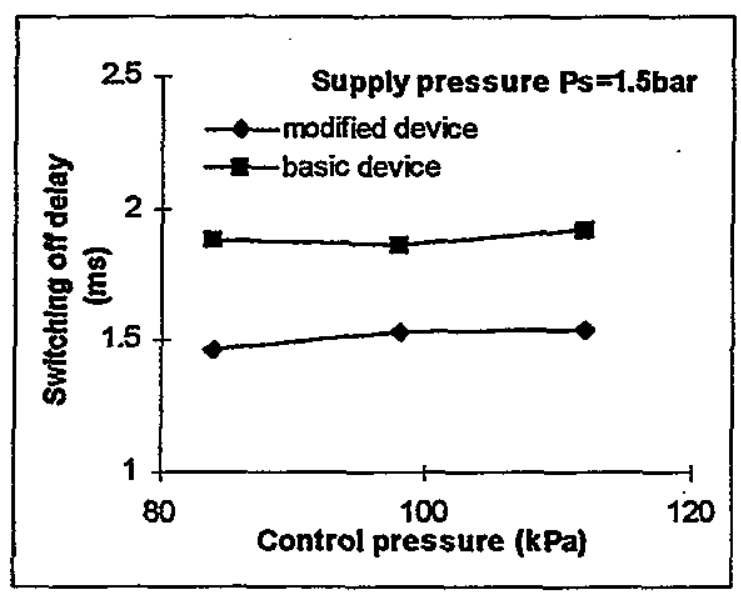

Figure 20 Response times (-off) from the basic device and the modified one (vacuum switching)

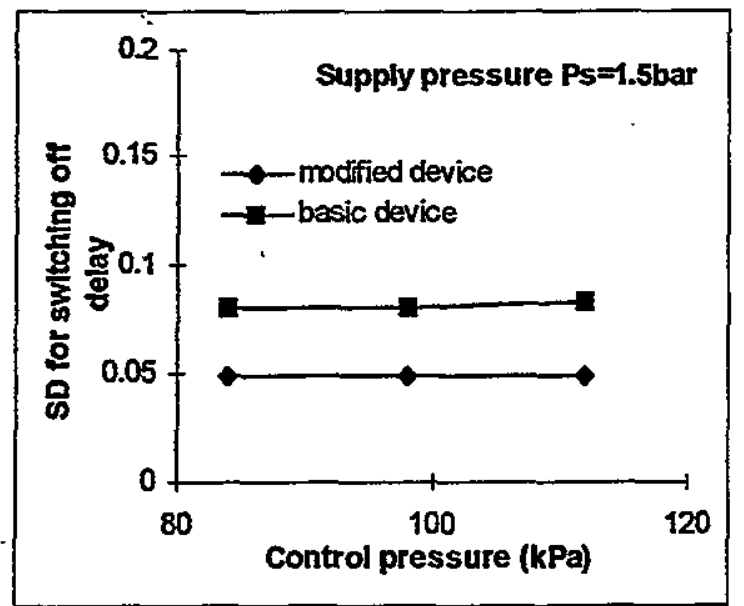

Figure 21 Standard deviations of the switching times from the basic device and the modified one 
If the response time of the solenoid (on delay is $1.1 \mathrm{~ms}$ and off delay is $0.9 \mathrm{~ms}$ ) is deducted from the above total response time ( $2.2 \mathrm{~ms}$ for on delay and $1.5 \mathrm{~ms}$ for off delay for a control pressure of 1 bar or $100 \mathrm{kPa}$ ), the switching-on and -off delays by the fluidic stage itself are $1.1 \mathrm{~ms}$ and $0.6 \mathrm{~ms}$ respectively. It will be seen later that both these delay times are further improved in the gas reservoir arrangement.

\section{RESERVOIR ENCLOSURE AND} DYNAMIC TESTS - The above tests on the fluidic device were carried out on an "open" test rig, in which supply flow is provided by a compressed air mains and the vents and outputs of the device were both open to atmosphere. In this section the proposed reservoir enclosure system (shown in Figure 2) was set up and the second fluidic device was tested in the reservoir environment.

Figure 22 shows the schematic set-up of the proposed system. A conventional three stage pressure regulator was used to bring a high pressure down to required levels. The output of the second stage pressure reduction was connected to the solenoid interface providing a control pressure of 1 bar for the fluidic switching. The output of the third stage, which is at an atmospheric pressure, is connected to a gas reservoir. The spill flow from the unstable output and the vent are also connected to this reservoir.

Both basic device and the modified version (with an internal connection) were tested. In Figure 22, a modified version of the device is shown. In the case of the basic device, the positive port and its vent are also connected to the gas reservoir. A recirculating pump is used to provide all the required supply flow to the device input nozzle. Figure $\mathbf{2 2}$ shows a practical implementation for the schematic arrangement shown in Figure 2.

It should be noted that a single operating point was identified with a supply pressure of 1.5 bar provided by the pump. An additional pressure transducer was fitted at the reservoir to detect its pressure variations. The operating characteristics of the basic device with the reservoir was compared with those in an "open" rig test, and evaluations on the modified device was also carried out on this reservoir test rig.

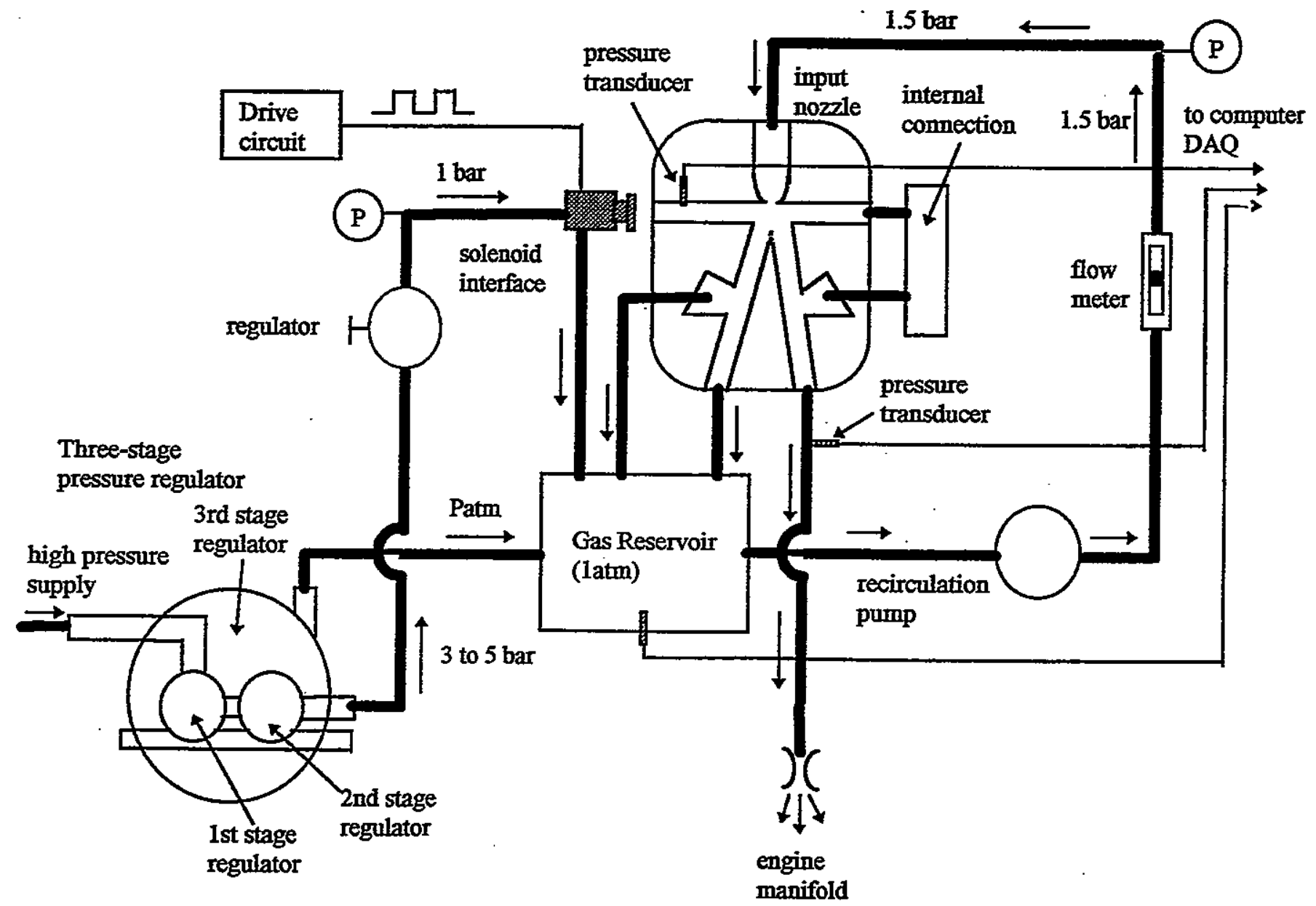

Figure 22 A schematic set-up for the reservoir and gas recirculating system test rig 


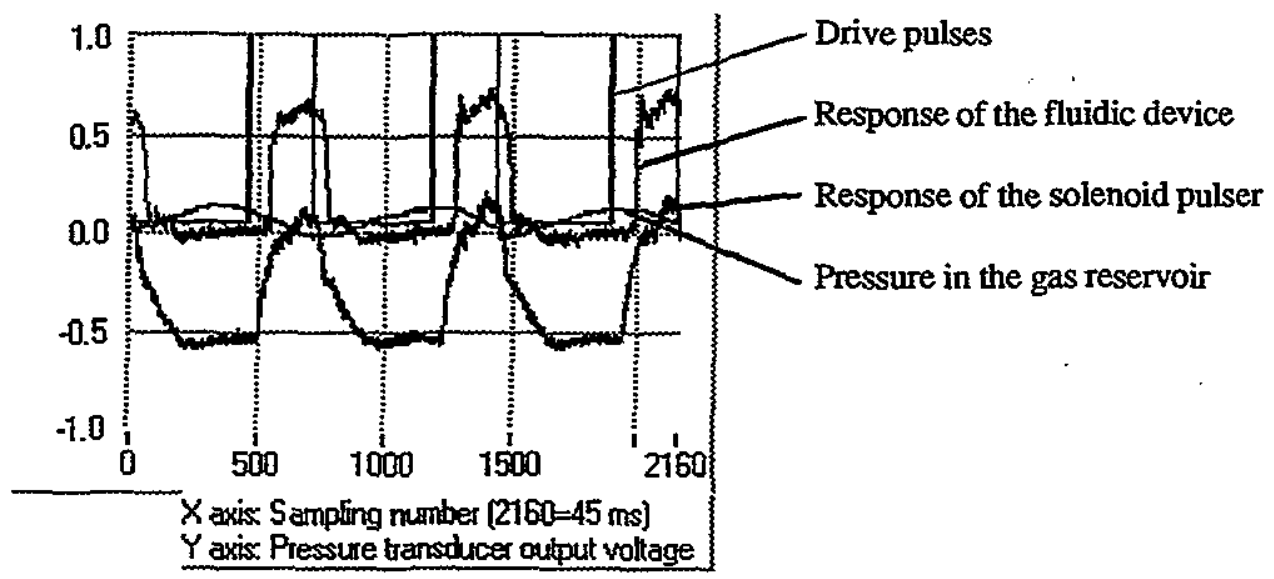

(Supply pressure $=20$ psi or $140 \mathrm{kPa}$, Control flow pressure $=14$ psi or $98 \mathrm{kPa}$, Average reservoir pressure $=0.85 \mathrm{psi}$ or $6 \mathrm{kPa}$ )

Figure 23 A plot of three pressure traces: control flow, fluidic output and the reservoir pressure

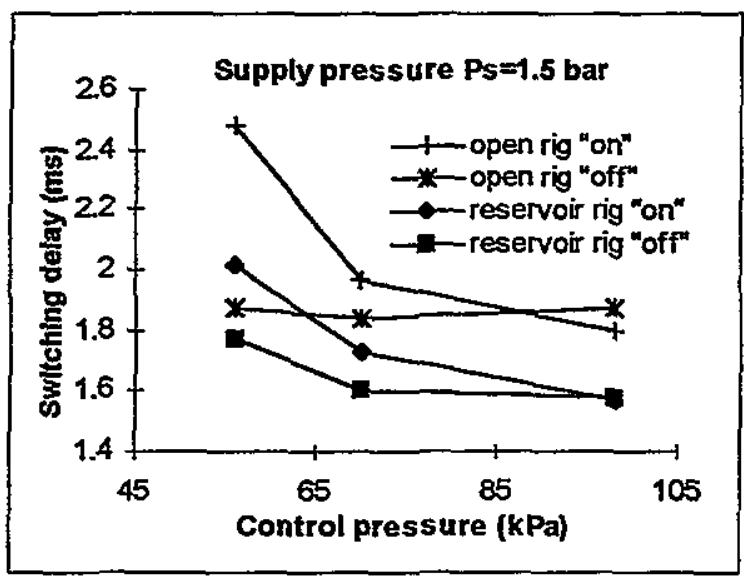

Figure 24 Switching responses of the basic device on both "open" and the reservoir test rig

Figure 23 shows a results from three pressure transducers. The supply pressure and control pressure used for the fluidic device were $140 \mathrm{kPa}$ (1.5 bar) and $98 \mathrm{kPa}$ (about $1 \mathrm{bar}$ ) respectively. The reservoir did show some pressure fluctuations as expected. However, the average value under this condition is only $6 \mathrm{kPa}$ and no significant effects on the switching characteristics on the fluidic stage were observed. The frequency of the pressure fluctuation in the reservoir depends on the pulse width and the Pulse Repeat Period (PRP) applied on the solenoid.

Figure 24 shows the comparison of the switching response of the basic device on both "open" and reservoir rig test. It can be seen that some small improvements were obtained for both switching-on and -off delays in the reservoir environment. This may be attributed to the presence of a slight positive pressure in the

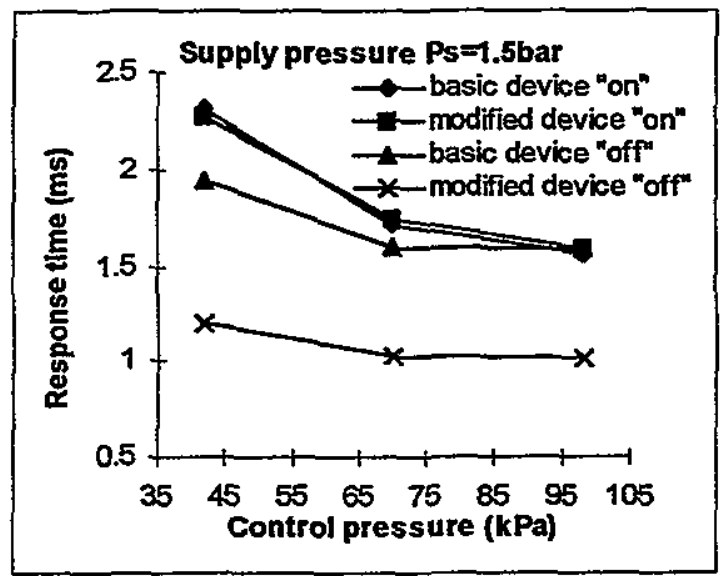

Figure 25 Switching responses of the basic device and the modified version on reservoir rig

reservoir, which has benefited both switching responses.

The use of internal connection to link the positive port and its vent together would further reduce the switching-off delay, as demonstrated earlier in the "open" rig test. Figure 25 shows comparison of the switching response of the basic device and the modified device on the reservoir test rig. It can be seen that there is a significant decrease (up to $42 \%$ ) in switching-off response time compared to the basic device arrangement.

For a control pressure of $100 \mathrm{kPa}$ (1 bar), the total switching-on and -off delays are $1.6 \mathrm{~ms}$ and $1 \mathrm{~ms}$ respectively. If the response of the solenoid (on delay of $1.1 \mathrm{~ms}$ and off delay of 0.9 $\mathrm{ms}$ ) is deducted from the total delay, the response of the fluidic device itself are $0.5 \mathrm{~ms}$ and $0.1 \mathrm{~ms}$ for switching-on and -off delay respectively. In other words, the total on and off response of the fluidic stage is merely $0.6 \mathrm{~ms}$. It is believed that 


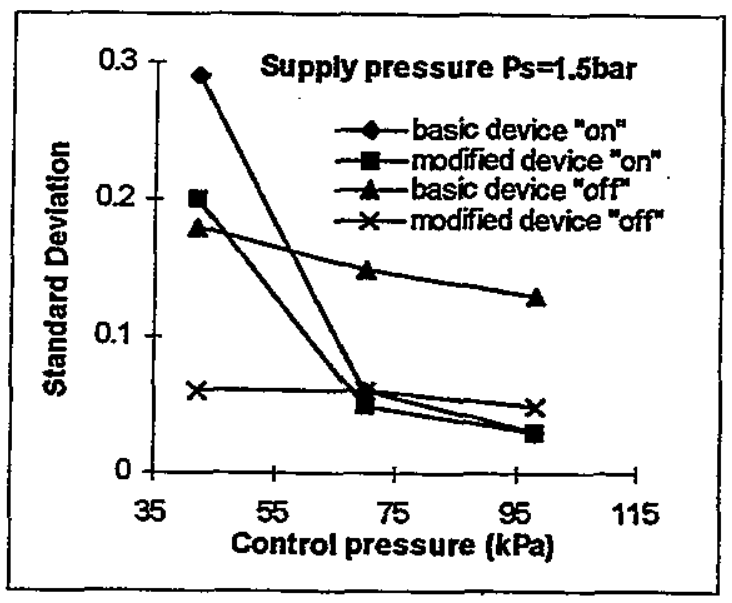

Figure 26 Standard deviations of the basic device and the modified one on a reservoir test rig there is a considerable potential of using these devices for fast response fuel injectors, and that when a faster, dedicated fluidic interface is developed, the performance of the fluidic injector unit will be comparable to that in current gasoline injectors.

Figure 26 shows SD's of the basic device and the modified device on the reservoir test rig. It can be seen that the switching-off repeatability has improved by $53 \%$ in the modified device and a very good cycle-cycle consistency with a SD of 0.06 was achieved for a control pressure of $100 \mathrm{kPa}$. Figure 27 to Figure 29 show the pressure trace and response results from 500 consecutive cycles in the modified device. Figure 30 to Figure 32 show the pressure trace and response results in the basic device for comparison. A supply pressure of 1.5 bar and a

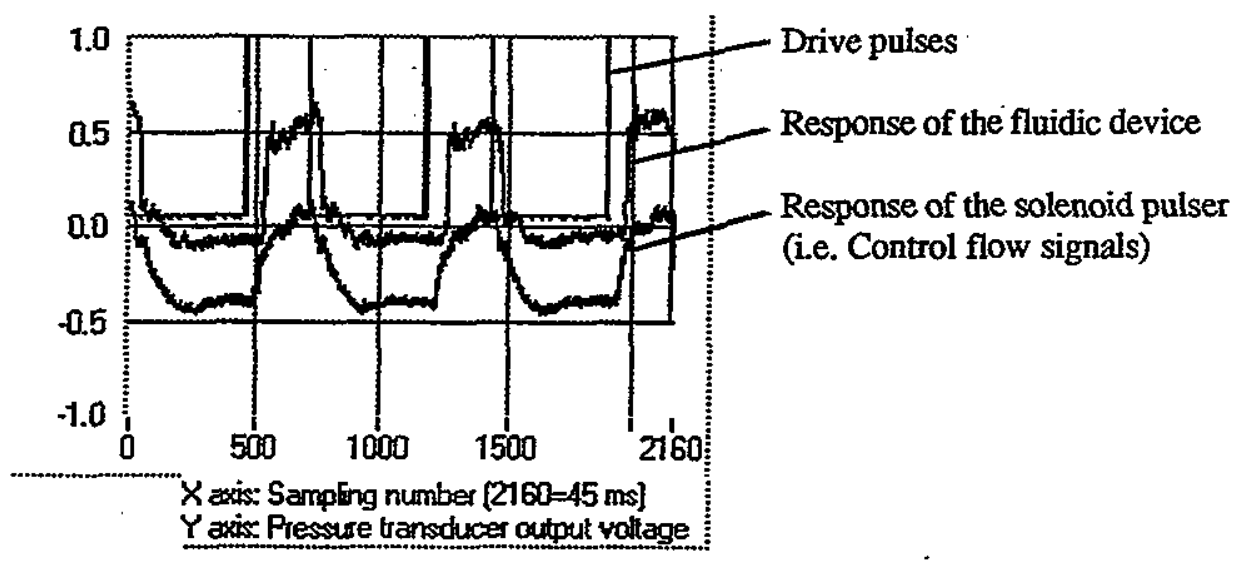

Figure 27 A plot of the pressure traces in the modified device

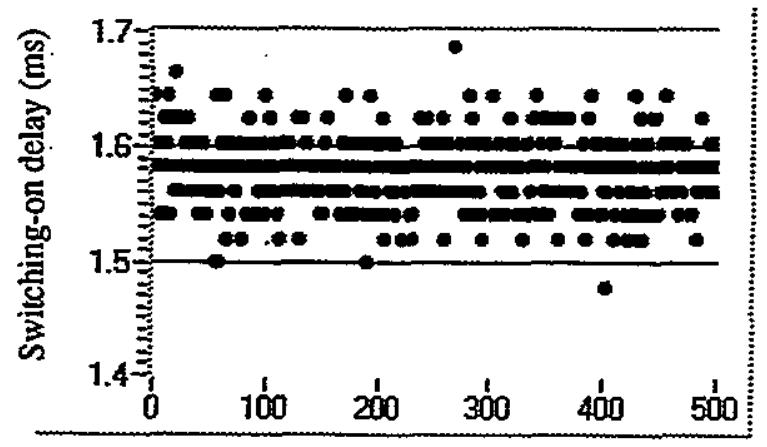

Average switching-on delay $=1.58 \mathrm{~ms}$,, $\mathrm{SD}=0.03$

Figure 28 Total switching-on time from 500 cycles by the modified device

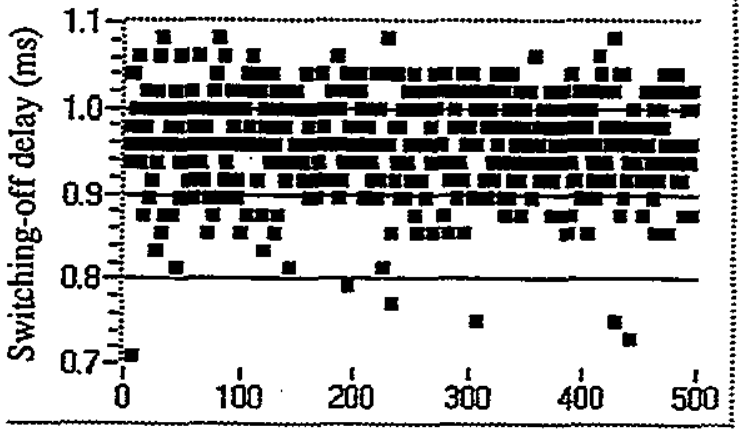

Average switching-off delay $=0.96 \mathrm{~ms}$., $\mathrm{SD}=0.06$

Figure 29 Total switching-off time from 500 cycles by the modified device 


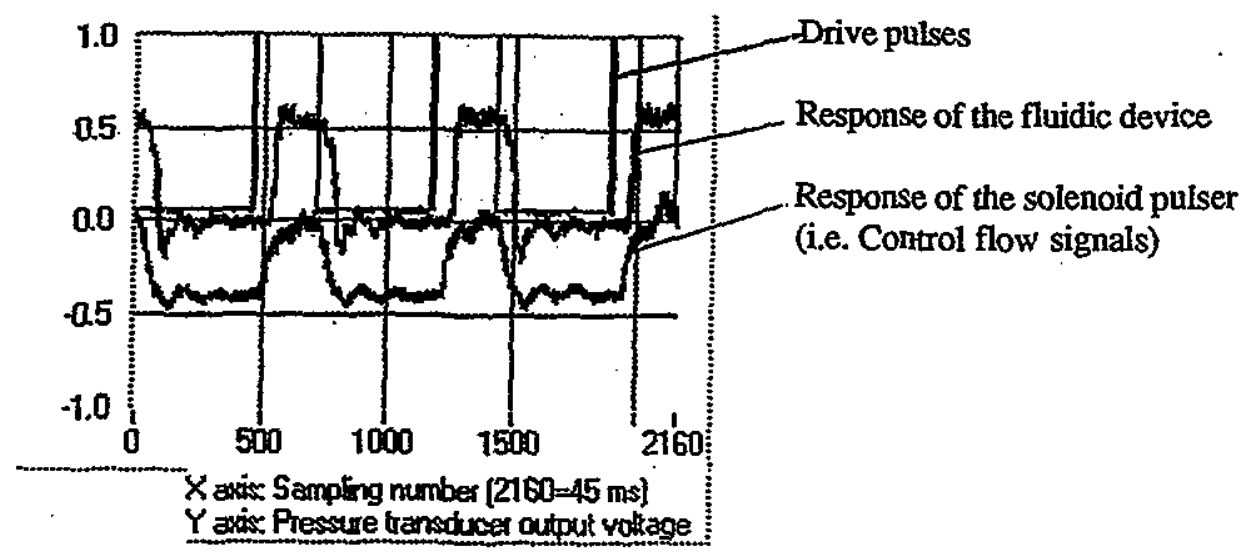

Figure 30 A plot of the pressure traces in the basic device

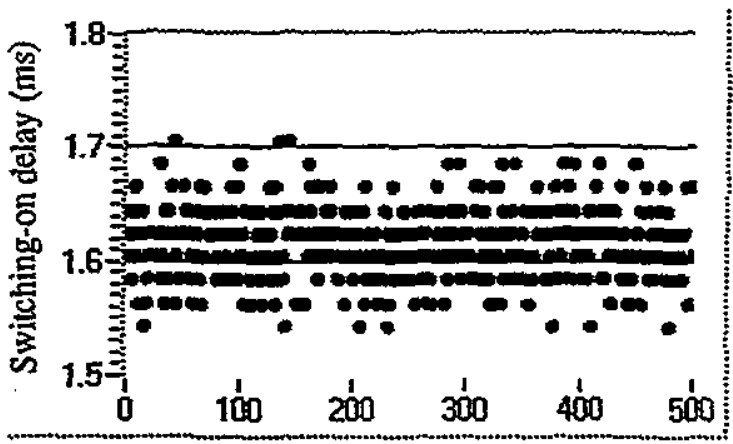

Average switching-on delay $=1.62 \mathrm{~ms} ., \mathrm{SD}=0.03$

Figure 31 Total switching-on response time from 500 cycles by the basic device

control pressure of 1 bar were used to produce these results.

DYNAMIC TESTS ON THE COMMERCIAL GAS INJECTORS - Three Servojet solenoid gas injectors (type SP-014, SP021 and SP-051) and one Bosch gas injector were obtained. No dynamic characteristics were provided by the manufacturers. It was therefore decided to carry out similar dynamic tests on these injectors in the laboratory test rig so that their switching performance can be compared with those from the fluidic injector unit.

Figure 33 shows the switching on response of these injectors under varying pressures. It is known that these injectors normally operate between 7 to 10 bars on gas engines. However, the maximum pressure used in the tests was $3.5 \mathrm{bar}(51 \mathrm{psi})$ due to limited peak pressure available in the laboratory. It can

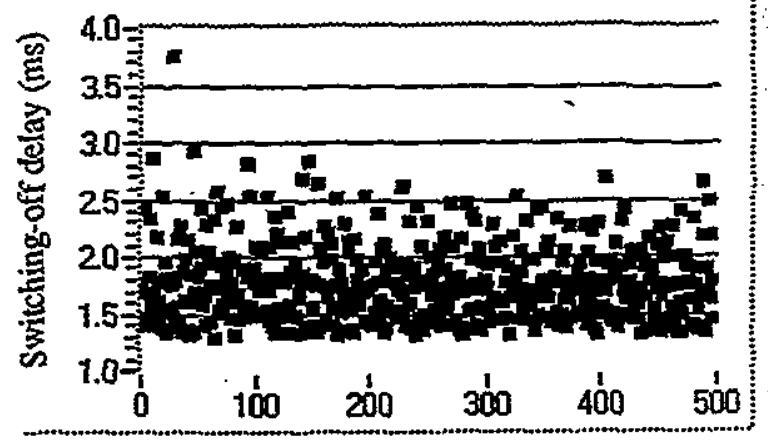

Average switching-off delay $=1.76 \mathrm{~ms}$., $\mathrm{SD}=0.34$

Figure 32 Total switching-off response time from 500 cycles by the basic device

be seen from the result in Figure 33 that the switching-on response time increases as the supply pressure increases for all four injectors. As mentioned earlier, the best switching-on time achieved by the fluidic unit (fluidic plus solenoid interface) is in the region of $1.6 \mathrm{~ms}$, it is therefore reasonable to predict that the fluidic unit has a faster switching speed than all these four injectors, when they operate at their normal pressure range.

Figure 34 shows the switching-off response of these injectors under varying pressures. The Bosch unit again showed the best response time $(1.4 \mathrm{~ms})$. However, the best switching-off time achieved by the fluidic unit (fluidic plus solenoid interface) is in the region of $1 \mathrm{~ms}$ (for a supply pressure of $1.5 \mathrm{bar}$ and a control pressure of 1 bar shown in Figure 25). It should be noted that the Bosch gas injector used here is a relatively small unit designed for gas engines possibly below a 2 litre capacity. 


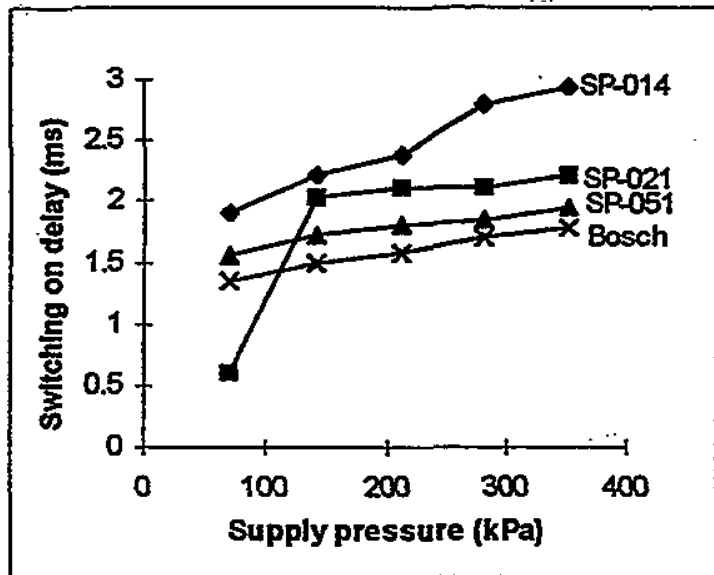

Figure 33 Switching-on response of the commercial gas injectors

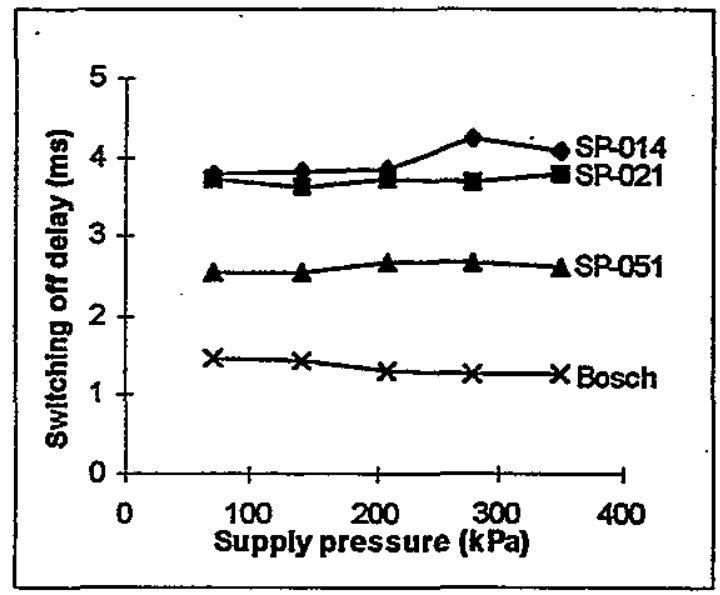

Figure 34 Switching-off response of the commercial gas injectors

Therefore it has advantages of light armature and small passage area, which results in its faster response than Servojet injectors.

Figure $35 \&$ Figure 36 show the standard deviation of the response time of these four injectors. It can be seen that the Bosch unit showed extremely consistent cycle-cycle variations with a SD of 0.02 for both switchingon and -off delays. This is largely due to its compact and light design for small flow capacity requirements. In comparison, the fluidic unit is capable of switching with SD of 0.05 and 0.06 for on and off response respectively.

\section{FUTURE WORK}

Future work will concentrate on evaluating the fluidic injector under a simulated engine

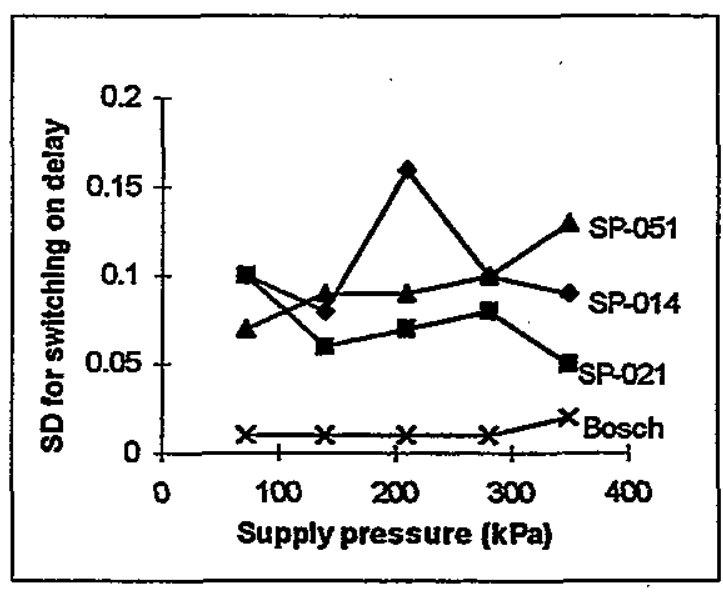

Figure 35 Standard deviations of the switchingon times from the commercial gas injectors

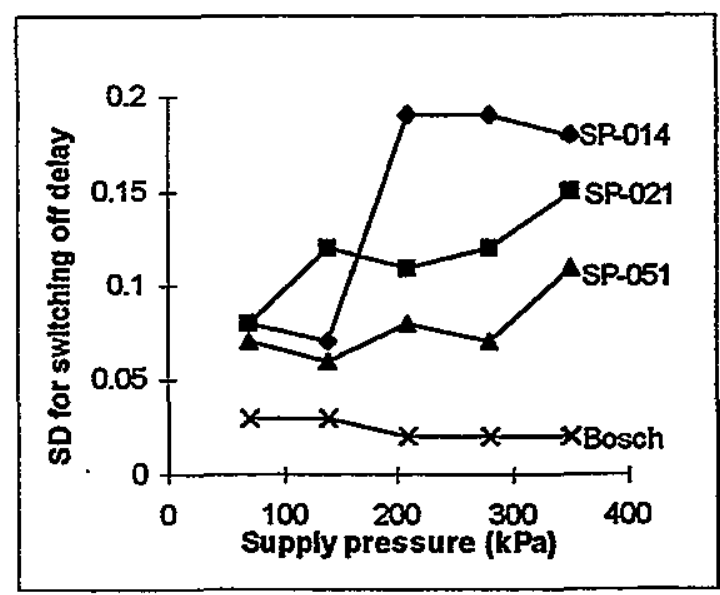

Figure 36 Standard deviations of the switchingoff times from the commercial gas injectors

vacuum condition in a laboratory test bench and carrying out comparative engine tests on an engine test bed. The purpose of the laboratory investigation is to ensure that the injector system operates satisfactorily before it is implemented on a research engine. The second purpose is to establish a suitable air-gas mixing nozzle or some sort of one-way diaphragm (or valve) to eliminate the effect of vacuum conditions on the fluidic stage.

When the laboratory test is complete, the fluidic injector will be implemented on a research engine so that its engine operating characteristics of the fluidic injector system can be compared with those from other gas injection systems and basic gas carburettor systems.

Efforts will also be made on developing a dedicated fluidic interface for the fluidic gas 
injector, as it was identified that the existing interface used in the fluidic unit has limited dynamic response. A novel piezo interface is under investigation for the fluidic gas injector.

\section{CONCLUSIONS}

[1] A novel gas fuel injector system based on the use of monostable fluidic devices is proposed in this paper. The system consists of non-moving-part fluidic devices, a solenoid interface and air-gas mixing nozzles. The operating principle of the proposed system was described and verified in experiments.

[2] Two prototype fluidic devices were produced and tested in the laboratory. Suitable operating points of the fluidic stage with required steady-state flow characteristics for gas injectors were identified.

[3] Dynamic tests on the first prototype device showed that switching from the stable output to the unstable output is sluggish with poor response characteristics and switching repeatability, regardless any switching method is used.

[4] A modified version of the basic fluidic device (second prototype) was proposed and tested on both an "open" test rig and a gas reservoir enclosure test rig. It was found that the modified version showed a considerably improved switching-off response for the vacuum method used while maintaining a fast switching-on response.

[5] The fluidic injector with a modified fluidic device can achieve switching-on response (fluidic plus solenoid) of $1.6 \mathrm{~ms}$ with a Standard Deviation (SD) of 0.03 , and switching-off response of $1 \mathrm{~ms}$ with a SD of 0.06 . If the response of the solenoid is deducted from the above values, the response of the fluidic device itself are $0.5 \mathrm{~ms}$ and $0.1 \mathrm{~ms}$ for switching-on and -off respectively.

[6] Comparing with commercial gas injectors, the fluidic injector has a faster dynamic response (on and off response) than all the commercial units tested and it has a smaller cyclecycle variations than the three Servojet injectors. However, the Bosch injector showed a slight better cycle-cycle switching repeatability than the fluidic unit.

[7] Future work will concentrate on engine tests of the fluidic injector and on developing a dedicated piezo interface for the fluidic device.

\section{ACKNOWLEDGEMENT}

The financial support from British Gas plc. for this project is gratefully acknowledged. The authors also wish to record their appreciation of technical assistance provided by Mr. Alan Brightwell, British Gas plc, Mr. John Elliott, Preci-Spark Ltd. U.K. and Technician Mr. D.M. Harkis, Loughborough University.

\section{REFERENCES}

1. J. Klimstra et al. "Catalytic Converters for Natural Gas Fuelled Engines - A Measurement and Control Problem". SAE paper 872165.

2. J. Klimstra et al. "Carburettors for Gaseous Fuel - On Air-fuel Ratio, Homogeneity and Flow Restriction". SAE paper 892141.

3. M. Perrault, G.Allard et al, "An Alternative to the Conventional Natural Gas Conversion Kit for Vehicales - Computer Controlled Upstream Injection" SAE paper 881659.

4. C. J. Green et al. "Electronically Actuated Injectors for Gaseous Fuels". SAE paper 892143.

5. Q. Huang et al. "Electro-fluidic Devices as Fuel Injectors for Spark-ignition Engine Fuel Injection Systems". SAE paper 910378 .

6. Q. Huang, B.Jones. "Evaluation of Engine Operating Characteristics of a Fluidic Device Based Fuel Injection Systems". 1993 SAE Transaction, No. 930324.

7. Q. Huang, D. Sansum, "The Investigation into a PC-based Fluidic Fuel Injection System for Passenger Cars", SAE Paper 950070.

8. R.A. Comparin, et al. "Fluid Switching Elements and Amplifiers". IBM Research Report RZ-94, July 231962. 